\title{
Iniencephaly Clausus: A New Case With Clinical and Imaging Findings
}

\author{
Alireza Khatami, ${ }^{1, *}$ Mohsen Hasanzadeh, ${ }^{1}$ Hedayat Norouzi, ${ }^{1}$ Ehasn Esfandiari, ${ }^{1}$ and Mas- \\ tooreh Mehrafarin ${ }^{1}$
}

${ }^{1}$ Department of Radiology, Mofid Children's Hospital, Shahid Beheshti University of Medical Sciences, Tehran, Iran

${ }^{*}$ Corresponding author: Alireza Khatami, Department of Radiology, Mofid Children's Hospital, Shahid Beheshti University of Medical Sciences, Tehran, Iran. Tel: +98-9121450832, E-mail: alireza_khatami31@yahoo.com

Received: March 12, 2012; Revised: August 12, 2013; Accepted: September 19, 2013

\begin{abstract}
Iniencephaly is a rare kind of neural tube defect that is classified into two types of iniencephaly apertus and iniencephaly clausus. This anomaly could be diagnosed prenatally by obstetric ultrasonography and terminated by therapeutic abortion; however, it could be undiagnosed until birth similar to our case due to the abnormal position of the fetus or lack of experience of the sonographer. Due to abnormality of the neural tube, which causes abnormal head and neck position, all these cases will die shortly after birth. We hereby introduce the photos and imaging findings of a case of an alive neonate with iniencephaly clausus.
\end{abstract}

Keywords: Neural Tube Defects; Diagnostic Imaging; Congenital Abnormalities

\section{Introduction}

Iniencephaly is a rare and fatal neural tube defect involving both the brain and the neck $(1,2)$. This entity was first described in 1836 by Saint-Hilaire (1). In 1897, Lewis mentioned two types of iniencephaly: iniencephaly clausus with spinal defect and no cephalocele, and iniencephaly apertus with spinal defect and cephalocele (3). It is a disorder that is defined by three characteristic findings including an occipital bone defect, spina bifida of the cervical vertebra, and increased lordosis with hyperextension of the cervical spine $(4,5)$. Incidence varies from 0.1 $-10 / 10,000$ and more than $90 \%$ of the patients are female $(6,7)$.

\section{Case Presentation}

A 25-year-old pregnant female (G2P2L1) with full-term pregnancy was referred for elective cesarean section due to polyhydramnios. The patient had a 3-year-old normal boy from her previous pregnancy. Unfortunately prenatal sonography only described polyhydramnios. Cesarean section was performed and a female newborn was delivered. The baby weighed $3250 \mathrm{~g}$. Extreme retroflexion of the head and left club foot were seen. Mild respiratory distress was noted. Cervicothoracic X-ray revealed cervical hyperextension (Figure $1 \mathrm{~A}-1 \mathrm{C}$ ).

Brain and thorax CT scan without contrast with coro- nal, sagittal and 3-dimensional reformatted images of the vertebra and chest wall were obtained. Images revealed absence of the posterior portion of the corpus callosum and prominent cerebellar cistern. Cerebellar vermis is not appreciated in the brain CT scan raising the possibility for agenesis. No brain MRI for correlation was available (Figure 2). Indeed, multiple bony abnormalities are visualized, composed of occipital bone defect around the foramen magnum causing a $2.5 \mathrm{~cm}$ widening of the foramen (Figure $3 \mathrm{~A}$ and 4 ), hyperextended cervical spines (Figures $3 \mathrm{~A}$ and $3 \mathrm{~B}$ ) as well as unfused posterior elements of cervical and thoracic spines (arrows in Figures 4 and 5), hemivertebra at T1 (Figures $3 \mathrm{C}$ and 3D), hypoplasia of the mandible, hypotelorism, posterior fusion of T10-T11-T12 and C5-C6-C7 (3D-images in Figure 4), bifid ribs with posterior fusion (ribs 3 and 4 , and 7 and 8) and anterior fusion (ribs 5 and 6) were seen (Figures 3C and 3D).

Transthoracic echocardiogram was done and ventricular septal defect (VSD) (apical), patent ductus arteriosus (PDA) and patent foramen ovale (PFO) were detected. Abdominopelvic sonography revealed smallsized kidneys for gestational age on both sides (right side was $35 \times 17 \mathrm{~mm}$ and left side was $33 \times 16 \mathrm{~mm})$. Other abdominal organs were normal. 

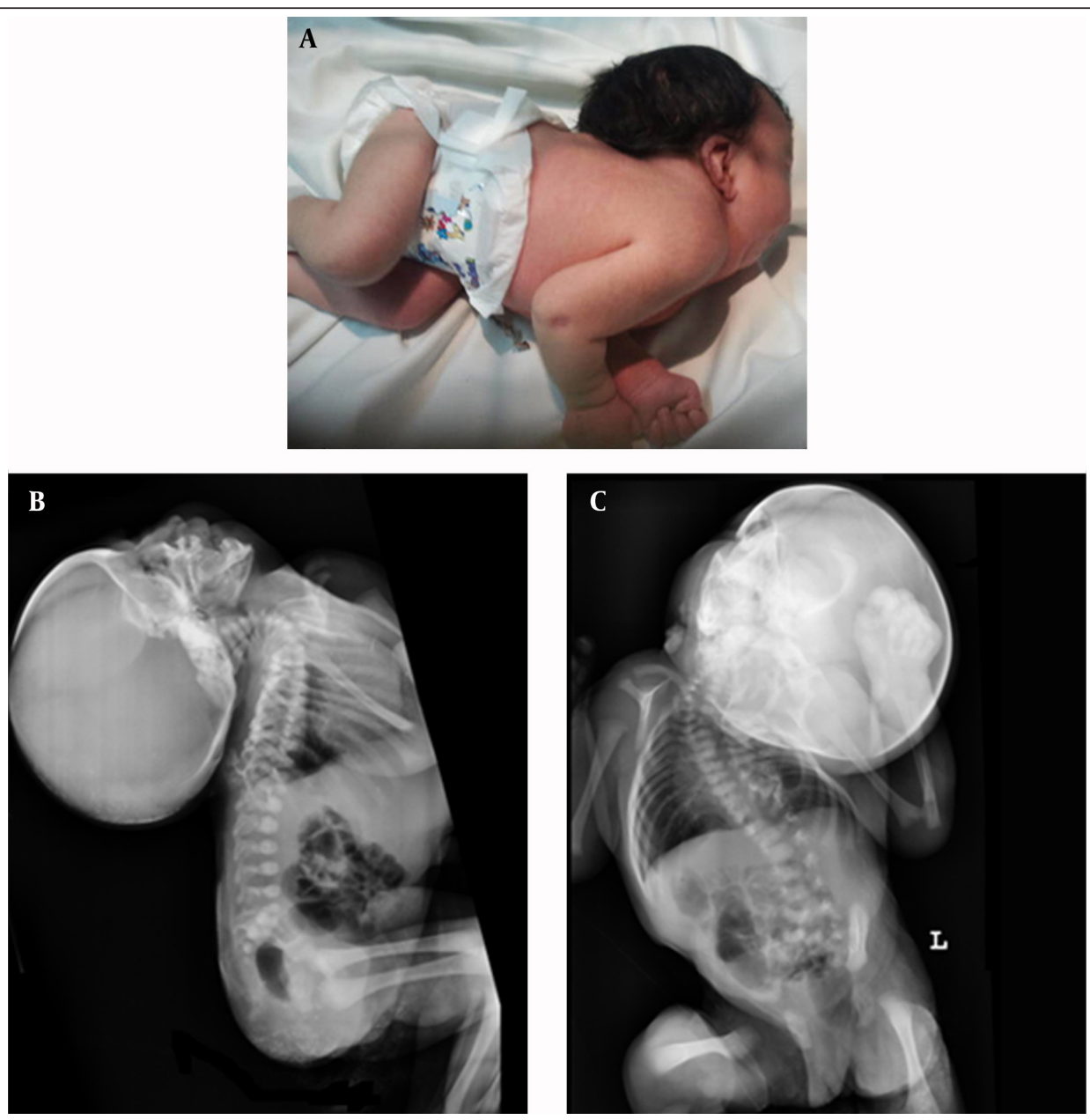

Figure 1. Newborn with iniencephaly. A, Photograph of the newborn shows retroflexion of the head and cervical spine. B, Lateral and C, AP cervicothoracic radiography images of the newborn show cervical hyperextension and T11 hemivertebra

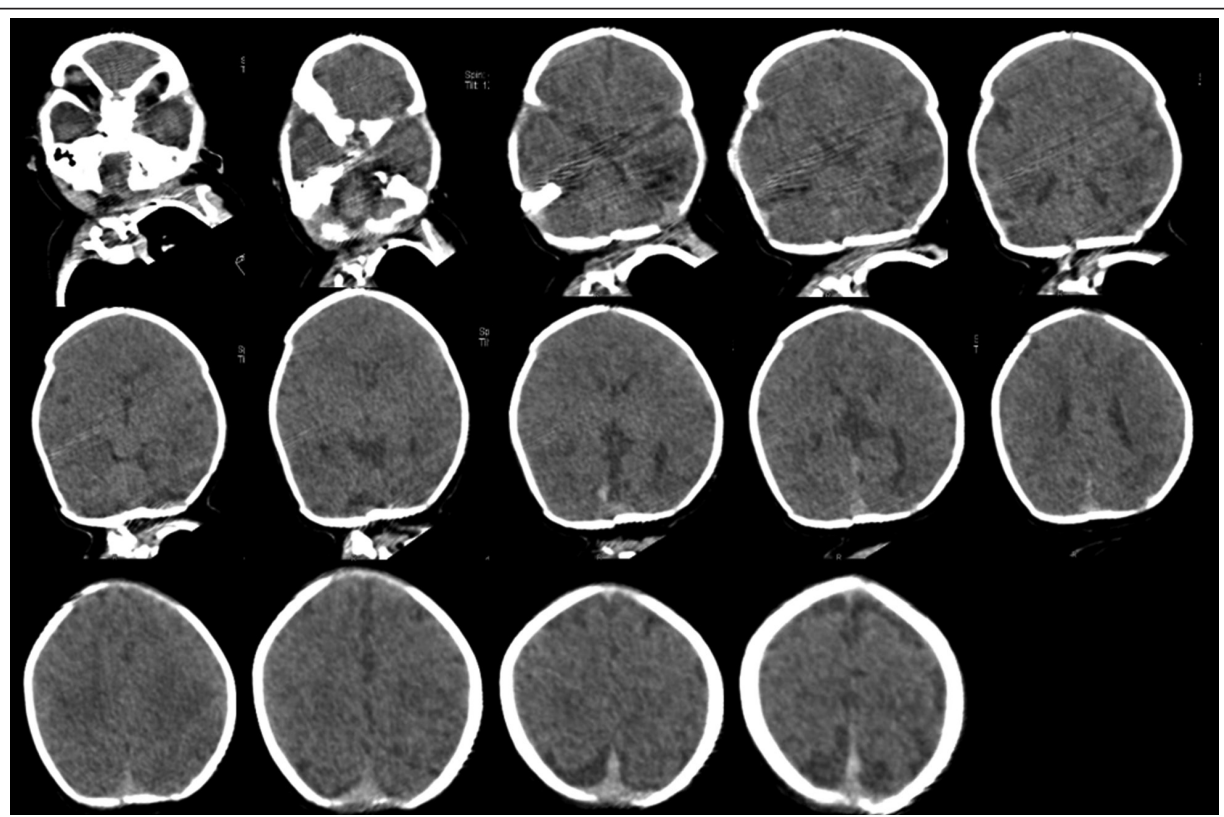

Figure 2. Axial brain CT scan reveals absence of the posterior part of the corpus callosum. There is suspicion of vermian agenesis. MRI was not performed to confirm. The head and thorax are adjacent to each other in the first image 
Khatami A et al.
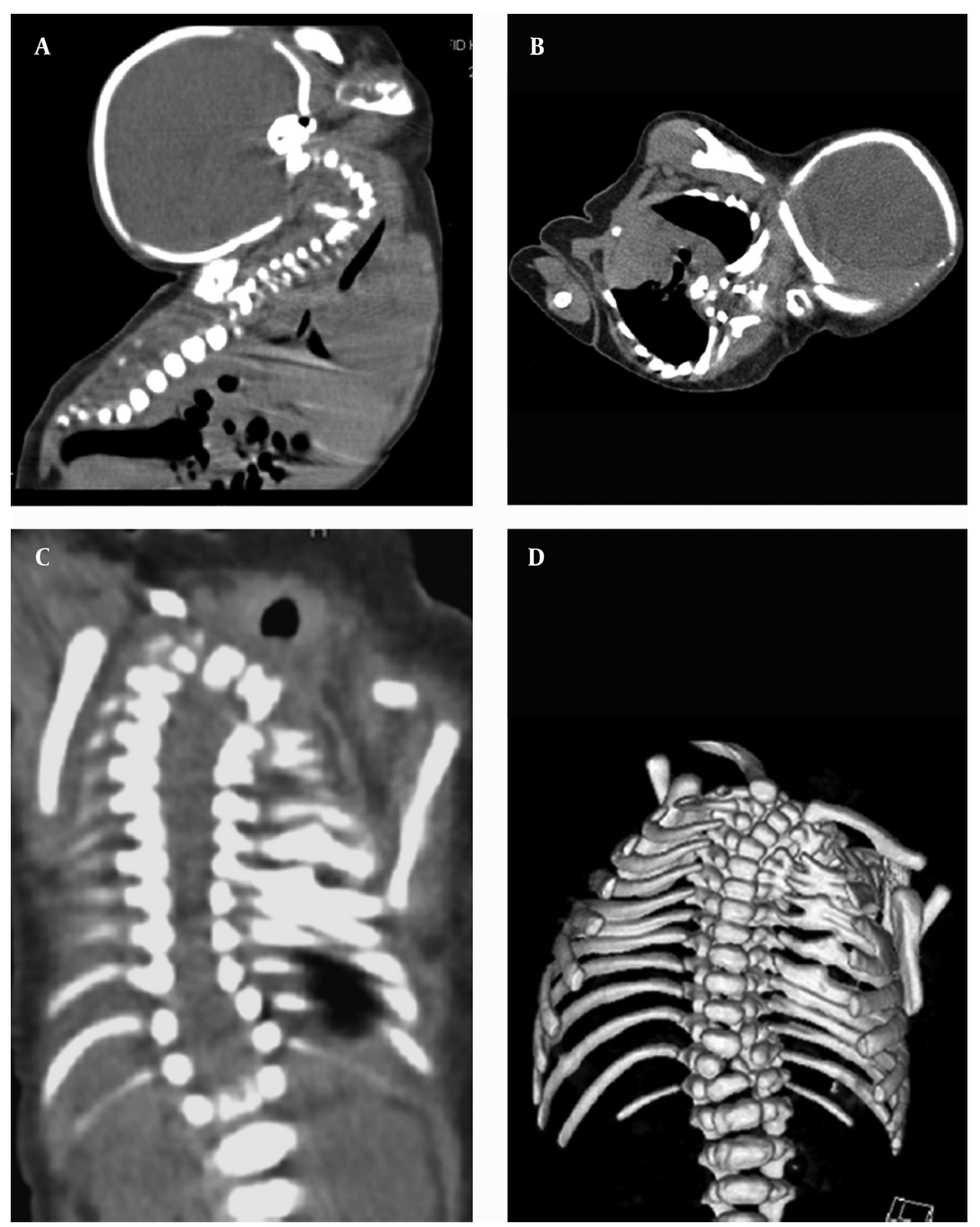

Figure 3. A, Sagittal reformatted MPR CT image of the cervicothoracolumbar spine shows cervical hyperextension and widening of the foramen magnum. B, Axial CT image at carina shows ribs fusion and cervical hyperextension in which the skull and thorax are seen side by side. C, Coronal reformatted CT image shows ribs deformities and D, 3-dimensional reconstruction of the vertebra and chest wall image reveals hemivertebra at T11, bifid ribs with posterior fusion (rib 3 and 4 , rib 7 and 8) and anterior fusion (rib 5 and 6 ) on the left side 


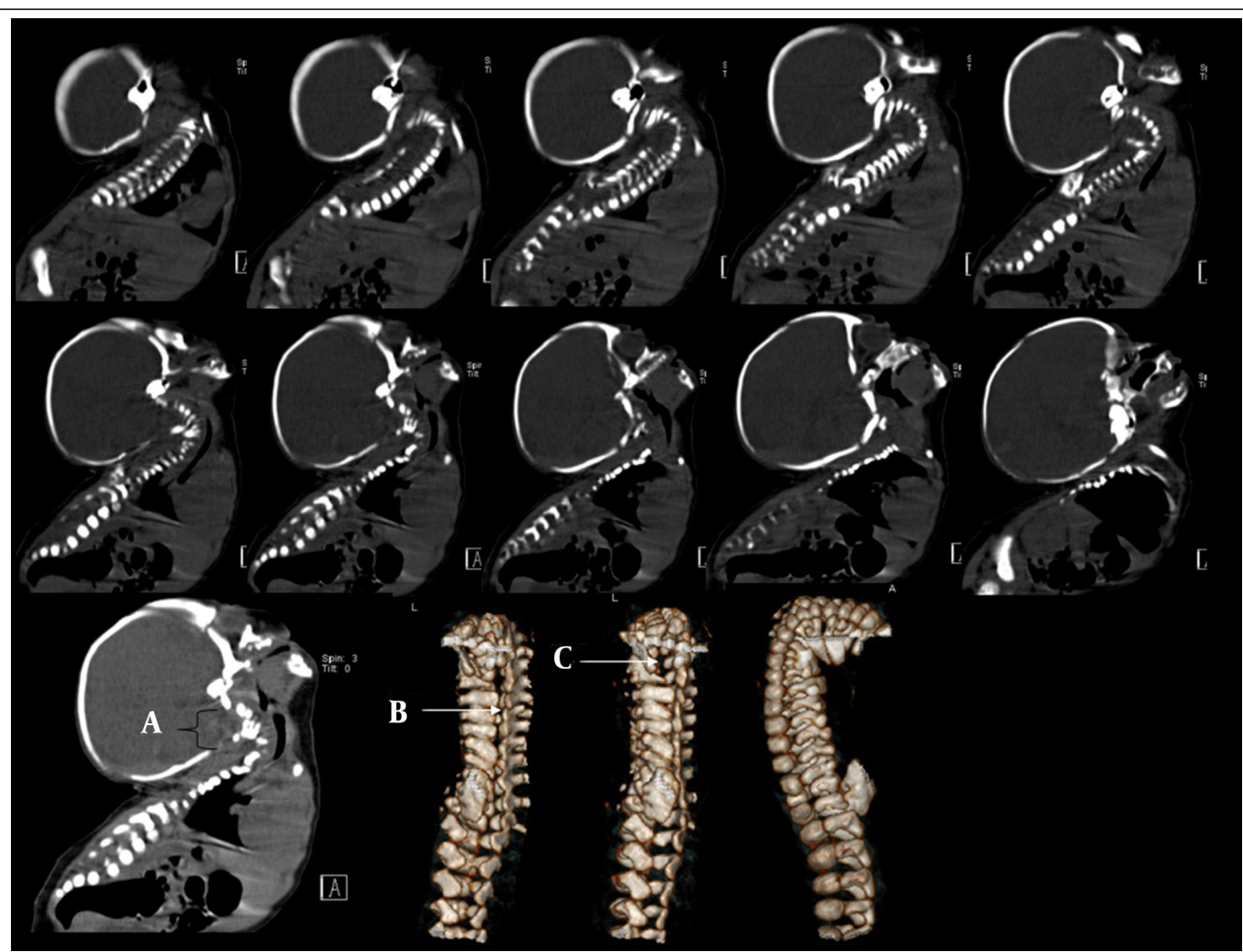

Figure 4. Sagittal reformatted and 3-dimensional volume rendered reconstructed images of the cervicothoracic spine. First 11 images of the sagittal reformatted image reveals occipital bone defect with $2.5 \mathrm{~cm}$ widening of the foramen magnum (A). The next three 3-D reconstruction images reveal spina bifida (arrows A and B) at the thoracic (arrow B) and superior cervical (arrow C) spine. Posterior fusion of C5-7 is best shown in the last 3-D image

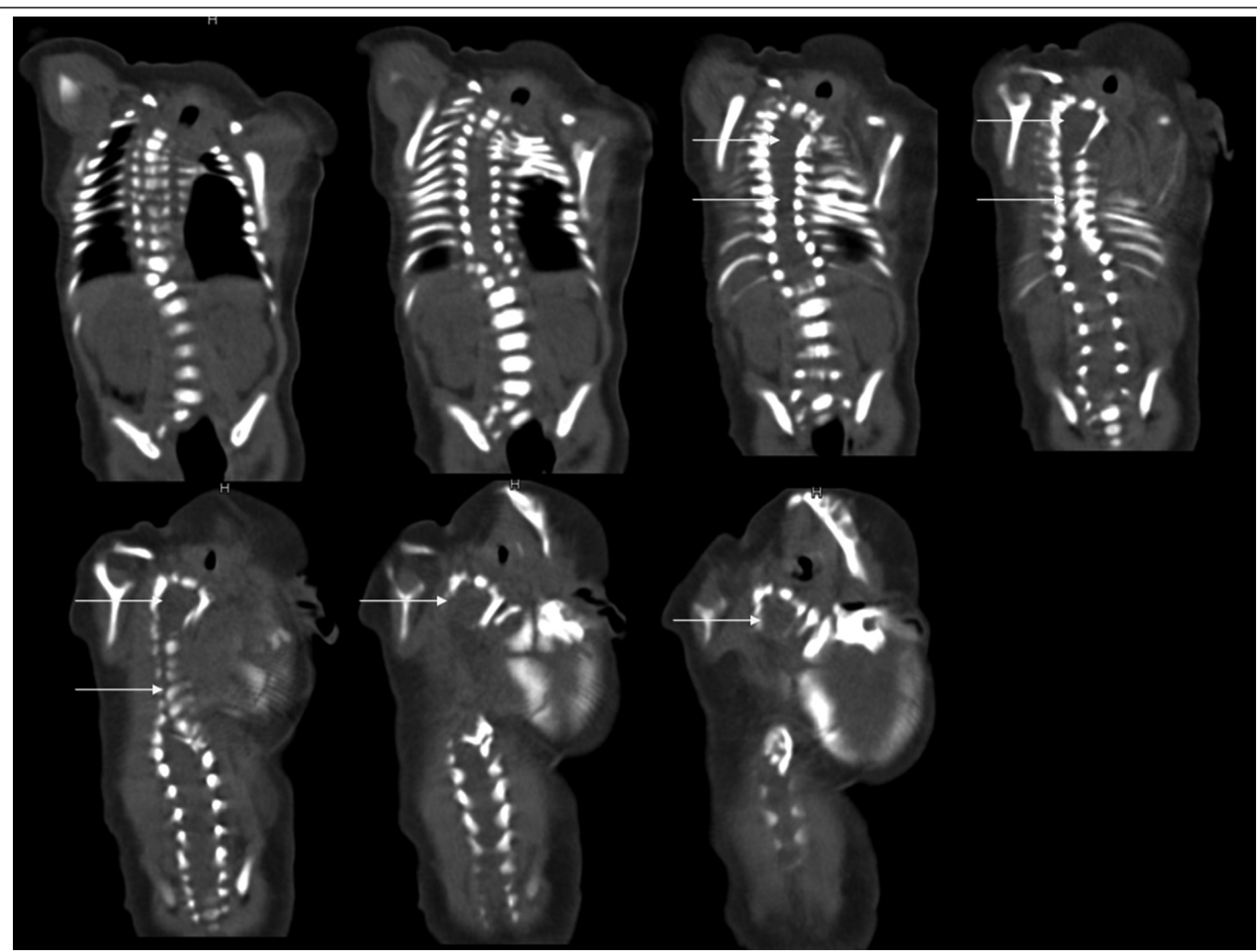

Figure 5. Coronal reformatted images of the spine. Arrows pointing to failure of posterior element fusion in the superior cervical and thoracic spines 


\section{Discussion}

There is no identified cause of iniencephaly. It is a rare neural tube defect with three distinctive features of occipital bone defect, cervicothoracic vertebral body abnormality as partial or total vertebral absence or fusion, and abnormal arch fusion. This anomaly causes cervical shortening and hyperextension of the cervicothoracic spine that leads to continuation of mandibular skin with the chest wall $(1,5,8)$.

In 1836, Saint Hilarie described iniencephaly for the first time. He assumed that the arrest of the embryo in physiological retroflexion during the 3rd week of gestation or failure of normal forward bending during the 4 th week could be the cause of this defect (1). In 1897, Lewis classified this defect into two types. The type with encephalocele was defined as iniencephalus apertus and the one without encephalocele as iniencephalus clausus (3). According to this classification, we described a new case of iniencepalus clausus. Associated anomalies with iniencephaly are separated to central nervous stystem (CNS) anomalies and non-CNS anomalies.

There are many CNS anomalies associated with iniencephaly such as microcephaly, polymicrogyria, holoprosencephaly, vermis agenesis, cerebellar cyst, encephalocele, cyclopia and atresia of the ventricular system. Our case showed partial agenesis of the corpus callosum with suspicion of vermian anomaly. The non-CNS anomalies reported in iniencephaly are facial dysmorphism, chest deformity, pulmonary hypoplasia, cheilognathopalatoschisis. Anomalies of the urinary, cardiovascular, skeletal and gastrointestinal systems seem to be more frequent. These associated anomalies may increase the fatality of iniencephaly and the necessity of a thorough workup in survivors (2). Again, our case revealed cardiac, bony thoracic cage and spinal anomalies.

Iniencephaly and anencephaly can manifest with congenital retroflexion of the spine. In addition, iniencephaly clausus should be differentiated from KlippelFiel syndrome and cervical meningomyelocele or teratoid masses (9). Anencephaly shows a total or partial absence of neurocranium. However, in iniencephaly, the retroflexed head is completely covered with skin. Cervical vertebrae are abnormal in iniencephaly and almost normal in anencephaly. Our case revealed retroflextion of the cervical spine with spinal dysraphysm that was completely covered by skin. About Klippel-Fiel syndrome and ineiencephaly, both have segmentation cervical spine anomaly; however, hyperextension is not seen in Klippel-Fiel syndrome (9).

Iniencephaly clausus a rare fatal congenital neural tube defect with a complex spine, CNS, and non CNS anomalies. Prenatal diagnosis is possible and differential diagnosis could be anencephaly, Klippel-Fiel syndrome with myelomeningoceles or neck masses. According to these gross skeletal abnormalities, this type of fetal anomaly could be seen very well by prenatal sonography so a more sophisticated sonography during pregnancy could find the anomaly in the first and second trimesters so the patient could be referred for legal abortion.

\section{Acknowledgements}

Acknowledgement to CT and radiology technicians of Mofid Children's hospital, Mrs. Marouf and Mr. Farjad.

\section{Authors' Contributions}

Alireza Khatami has the main contribution. Mohsen Hasanzadeh performed ultrasonography, case followup, and reviewed the article. Hedayat Norouzi and Ehsan Esfandiari were responsible for case follow-up. Mastooreh Mehrafarin reviewed the article and gathered the data.

\section{References}

1. Pungavkar SA, Sainani NI, Karnik AS, Mohanty PH, Lawande MA, Patkar DP, et al. Antenatal diagnosis of iniencephaly: sonographic and MR correlation: a case report. Korean J Radiol. 2007;8(4):351-5.

2. Joo JG, Beke A, Papp C, Szigeti Z, Csaba A, Papp Z. Major diagnostic and pathological features of iniencephaly based on twenty-four cases. Fetal Diagn Ther. 2008;24(1):1-6.

3. Gartman JJ, Melin TE, Lawrence WT, Powers SK. Deformity correction and long-term survival in an infant with iniencephaly. Case report.J Neurosurg. 1991;75(1):126-30.

4. Erdincler P, Kaynar MY, Canbaz B, Kocer N, Kuday C, Ciplak N. Iniencephaly: neuroradiological and surgical features. Case report and review of the literature. J Neurosurg. 1998;89(2):317-20.

5. Tugrul S, Uludogan M, Pekin O, Uslu H, Celik C, Ersan F. Iniencephaly: Prenatal diagnosis with postmortem findings. J Obstet Gynaecol Res. 2007;33(4):566-9.

6. Aytar MH, Dogulu F, Cemil B, Ergun E, Kurt G, Baykaner K. Iniencephaly and long-term survival: a rare case report. Childs Nerv Syst. 2007;23(6):719-21.

7. Romero R, Pilu G, Jeanty P, Ghidini A, Hobbins JC. Prenatal diagnosis of congenital anomalies. Norwalk, CT: Appleton and Lange; 1988.

8. Chen CP. Prenatal diagnosis of iniencephaly. Taiwan JObstet Gynecol. 2007;46(3):199-208.

9. Kulkarni PR, Rao RV, Alur MB, Joshi SK. Iniencephaly clausus: A case report with review of literature. J Pediatr Neurosci. 2011;6(2):121-3. 